\title{
Diagnostic Accuracy of Stool Tests for Colorectal Cancer Surveillance in Hodgkin Lymphoma Survivors
}

\author{
Berbel Ykema ${ }^{1}$, Lisanne Rigter ${ }^{1}$, Manon Spaander ${ }^{2}$, Leon Moons ${ }^{3}$, Tanya Bisseling ${ }^{4}$, \\ Berthe Aleman ${ }^{5}$, Jan Paul de Boer ${ }^{6}{ }^{\circledR}$, Pieternella Lugtenburg ${ }^{7}$, Cecile Janus ${ }^{8}$, Eefke Petersen ${ }^{9}$, \\ Judith Roesink ${ }^{10}$, John Raemaekers ${ }^{11}$, Richard van der Maazen ${ }^{12}$, Iris Lansdorp-Vogelaar ${ }^{13}$, \\ Andrea Gini ${ }^{13}$, Wieke Verbeek ${ }^{1}$, Margriet Lemmens ${ }^{14}$, Gerrit Meijer ${ }^{14}$, Flora van Leeuwen ${ }^{15}$, \\ Petur Snaebjornsson ${ }^{14}$, Beatriz Carvalho ${ }^{14}$ and Monique van Leerdam ${ }^{1,16, *}$
}

1 Department of Gastroenterology, Netherlands Cancer Institute, 1066 CX Amsterdam, The Netherlands; b.ykema@nki.nl (B.Y.); 1.rigter@nki.nl (L.R.); w.verbeek@nki.nl (W.V.)

2 Department of Gastroenterology and Hepatology, Erasmus MC, University Medical Center, 3015 GD Rotterdam, The Netherlands; v.spaander@erasmusmc.nl

3 Department of Gastroenterology and Hepatology, University Medical Center Utrecht, 3584 CX Utrecht, The Netherlands; l.m.g.moons@umcutrecht.nl

4 Department of Gastroenterology and Hepatology, Radboud University Medical Center, 6525 GA Nijmegen, The Netherlands; tanya.bisseling@radboudumc.nl

5 Department of Radiation Oncology, Netherlands Cancer Institute, 1066 CX Amsterdam, The Netherlands; b.aleman@nki.nl

6 Department of Medical Oncology, Netherlands Cancer Institute, 1066 CX Amsterdam, The Netherlands; j.d.boer@nki.nl

7 Department of Hematology, Erasmus MC Cancer Institute, 3015 GD Rotterdam, The Netherlands; p.lugtenburg@erasmusmc.nl

8 Department of Radiation Oncology, Erasmus MC Cancer Institute, 3015 GD Rotterdam, The Netherlands; c.janus@erasmusmc.nl

9 Department of Hematology, University Medical Center Utrecht, 3584 CX Utrecht, The Netherlands; e.j.petersen@umcutrecht.nl

10 Department of Radiation Oncology, University Medical Center Utrecht, 3584 CX Utrecht, The Netherlands; j.m.roesink@umcutrecht.nl

11 Department of Hematology, Radboud University Medical Center, 6525 GA Nijmegen, The Netherlands; johnmienraemaekers@gmail.com

12 Department of Radiation Oncology, Radboud University Medical Center, 6525 GA Nijmegen, The Netherlands; richard.vandermaazen@radboudumc.nl

13 Department of Public Health, Erasmus MC, 3015 GD Rotterdam, The Netherlands; i.vogelaar@erasmusmc.nl (I.L.-V.); a.gini@erasmusmc.nl (A.G.)

14 Department of Pathology, Netherlands Cancer Institute, 1066 CX Amsterdam, The Netherlands; m.lemmens@nki.nl (M.L.); g.meijer@nki.nl (G.M.); p.snaebjornsson@nki.nl (P.S.); b.carvalho@nki.nl (B.C.)

15 Department of Epidemiology, Netherlands Cancer Institute, 1066 CX Amsterdam, The Netherlands; f.v.leeuwen@nki.nl

16 Department of Gastroenterology and Hepatology, Leiden University Medical Center, 2333 ZA Leiden, The Netherlands

* Correspondence: m.v.leerdam@nki.nl; Tel.: +31-20-512-9111

Received: 12 December 2019; Accepted: 8 January 2020; Published: 10 January 2020

Abstract: Background: Hodgkin lymphoma (HL) survivors have an increased colorectal cancer (CRC) risk. Diagnostic accuracy of quantitative fecal immunochemical testing (FIT, OC Sensor) and/or a multi-target stool DNA test (mt-sDNA, Cologuard ${ }^{\circledR}$ ) for advanced neoplasia (AN) was evaluated. Methods: $101 \mathrm{HL}$ survivors underwent a surveillance colonoscopy and were asked to perform two stool tests (FIT and mt-sDNA). Advanced adenoma (AA), advanced serrated lesion (ASL), and AN (AA, ASL, CRC) were evaluated. Sensitivity, specificity, and area under the curve (AUC) for AN were calculated for different FIT cut-offs and mt-sDNA with colonoscopy as reference. Results: FIT and 
mt-sDNA were analyzed in $73(72 \%)$ and $82(81 \%)$ participants, respectively. AN was detected in $19(26 \%)$ and $22(27 \%)$, respectively. AN sensitivities for FIT cut-off of $10 \mathrm{ug} \mathrm{Hb} / \mathrm{g}$ feces (FIT10) and mt-sDNA were $37 \%$ (95\% confidence interval (CI): 16-62) and 68\% (95\% CI: 45-86), with corresponding specificities of $91 \%$ (95\% CI: 80-97) and 70\% (95\% CI: 57-86), respectively. AUC for FIT was 0.68 (95\% CI: 0.54-0.82) and for mt-sDNA 0.76 (95\% CI: 0.63-0.89). Conclusions: In HL survivors, mt-sDNA showed highest sensitivity but with relatively low specificity for AN. Cost-effectiveness analyses is necessary to determine the optimal surveillance strategy.

Keywords: early detection of cancer; sensitivity and specificity; cancer survivors; Hodgkin lymphoma; colorectal cancer; multi-target stool test; fecal immunochemical testing (FIT)

\section{Introduction}

Hodgkin lymphoma (HL) survivors treated with abdominal radiotherapy and/or procarbazine-containing chemotherapy have an increased risk of developing colorectal cancer (CRC) with a relative risk reported between 2 and 7 [1-6]. A recent prospective colonoscopy study showed a high yield of advanced adenoma (AA) and advanced serrated lesions (ASL) in HL survivors at a younger age compared with the general population. Therefore, colonoscopy surveillance is recommended from the age of 35 or eight years after HL treatment $[7,8]$. Yet, colonoscopy is burdensome and has a small risk of serious complications [9-11]. For this reason, the accuracy of non-invasive surveillance modalities for HL survivors needs to be assessed.

The fecal immunochemical test (FIT) is used for population-based CRC screening in the Netherlands [12-16]. This quantitative FIT detects human hemoglobin in feces and the positivity cut-off can be defined based on test performances. The FIT is easy to use and acceptance among the Dutch general population is high [17-20]. Participants with a positive stool test are referred for colonoscopy. An alternative stool test is the multi-target stool DNA test (mt-sDNA test, Exact Sciences, Madison, WI, USA). The latter detects, besides the presence of hemoglobin, altered DNA of colorectal neoplasia by sensitive analyses that target specific genetic and epigenetic biomarkers. Mt-sDNA has a higher sensitivity for detecting advanced colorectal neoplasia (AN—defined as AA, ASL, or CRC) compared to FIT [21-25]. FIT is currently considered inadequate for high-risk populations such as Lynch syndrome and individuals with familial risk of CRC, because of a relatively low sensitivity for AN. Therefore, these patients are offered periodic colonoscopy surveillance [26-28]. For HL survivors with a known increased risk of developing CRC, the effectiveness of stool tests has not yet been assessed.

HL survivors might benefit from a more personalized approach for CRC surveillance due to the young age of developing AN, more right-sided lesions, other histology (high frequency of serrated polyps), and psychological burden of colonoscopy [7]. Stool tests could be an alternative for colonoscopy surveillance and could increase the participation rate of CRC surveillance in HL survivors. A higher participation rate will eventually result in a higher detection rate of $\mathrm{AN}$, leading to a reduction of CRC incidence.

This study will evaluate the diagnostic accuracy of FIT and/or mt-sDNA in HL survivors with colonoscopy as a reference. Stool test performance is one aspect to define the most optimal surveillance program. Based on stool test performance, further analyses can be performed to determine the optimal surveillance program for HL survivors being primary colonoscopy or stool test with a subsequent colonoscopy for participants with a positive test. 


\section{Materials and Methods}

\subsection{Study Population}

Individuals were included in a prospective multicenter cohort study evaluating yield of colonoscopy in HL survivors. The study design and the diagnostic yield of colonoscopy in the study population were described previously $[7,29]$. Inclusion criteria for colonoscopy were infradiaphragmatic radiotherapy consisting of at least para-aortic and iliac fields, chemotherapy containing a cumulative procarbazine dosage of $\geq 2.8 \mathrm{~g} / \mathrm{m}^{2}$ or infradiaphragmatic radiotherapy (any field(s) and chemotherapy (any regimen)). A total of $101 \mathrm{HL}$ survivors underwent a colonoscopy between February 2015 and February 2017 at four Dutch study centers (the Netherlands Cancer Institute in Amsterdam, Erasmus MC Cancer Institute in Rotterdam, the University Medical Center in Utrecht, and Radboud University Medical Center in Nijmegen). Written informed consent was obtained from all participants who agreed to participate in the evaluation of the stool tests. Participants with an incomplete colonoscopy were excluded from analysis. The study was approved by the Medical Ethical Committee of the Netherlands Cancer Institute and was registered at the Dutch Trial Registry (ID NTR4961).

\subsection{Stool Collection}

Participants were invited to collect stool at home from one bowel movement prior to the start of the bowel preparation for colonoscopy. The two FIT tests as well as the mt-sDNA were performed on the same stool specimen with the request to deliver the stool within $60 \mathrm{~h}$ after collection (to minimalize the risk of DNA degradation). No restrictions were given for diet or medication prior to the collection.

\subsection{Fecal Immunochemical Test}

All the individuals included in the colonoscopy study were invited to perform two separate FIT tests (OC-Sensor, Eiken Chemical, Tokyo, Japan) on the same stool sample prior to colonoscopy. Participants received specific instructions on how to perform the FIT. The tip of the device should be stacked into the stool on three different spots and then put into the buffer in the test-kit. At the time of collection, participants were asked to annotate the date and time of collection.

After stool sample collection, the two tests were sealed in plastic bags and stored in the fridge until the appointment for the colonoscopy. Once present at the colonoscopy center, the samples were sent to the laboratory, at the Netherlands Cancer Institute in Amsterdam, working based on the demands of ISO 15189 but not (yet) accredited. Upon arrival at the laboratory, FIT samples were stored at $20{ }^{\circ} \mathrm{C}$ and analyzed between 4 weeks after storage to avoid degradation of hemoglobin. Analysis was performed according to the manufacturer's instruction by a trained technician, yielding quantitative measures of $\mathrm{Hb}$ concentration.

As FIT is a quantitative assay, different pre-determined cut-offs for positivity could be evaluated, specifically 10, 15, and $20 \mu \mathrm{g} \mathrm{Hb/g}$ feces, referred to as FIT10, FIT15, and FIT20, respectively. Two FIT tests were evaluated and the highest measured concentration was used.

\subsection{Multi-Target Stool DNA Test}

The multi-target stool DNA test (mt-sDNA, Cologuard ${ }^{\circledR}$, Exact Sciences Corporation, Madison, WI, USA) was also analyzed. All colonoscopy participants received a container for stool sample collection and written information. Stool was collected in the provided container. The stool stabilization buffer (Exact Sciences, Madison, WI, USA) was added to the stool sample by the participant directly after sample collection (and after the two FIT tests were performed). On the lid of the container, the date and time of bowel movement was stated by the participant and the container was kept at room temperature until brought to the laboratory.

The samples were processed in the laboratory with a final stool: buffer $w / v$ ratio of 1:4, separated into aliquots, and stored at $-80{ }^{\circ} \mathrm{C}$ until analysis. Exact Sciences Laboratory (Madison, WI, USA) performed the analyses of the mt-sDNA, as described before [24]. This laboratory is Clinical Laboratory 
Improvement Amendents (CLIA) licensed and College of American Pathologists (CAP) accredited. Mt-sDNA comprises, next to an immunochemical assay for human $\mathrm{Hb}$, molecular assays for mutations of KRAS (in codon 12 referred to as KRAS1; and in codon 13 referred to as KRAS2) and epigenetic silencing (hypermethylation) of NDRG4 and BMP3 promoter regions. As a reference gene for human DNA quantity, $\beta$-actin is also included in this molecular assay. Of each marker, quantitative measurements were retrieved separately. For $\mathrm{Hb}$, the cut-off used was $60 \mu \mathrm{g} \mathrm{Hb} / \mathrm{g}$ feces (i.e., $600 \mathrm{ng} \mathrm{Hb} / \mathrm{mL}$ buffer). A prespecified logistic regression algorithm combining the results of the different markers gives the final mt-sDNA result [24]. Calling of an individual test as positive or negative was done using the screening-validated threshold of 183 [24].

\subsection{FIT and $M t-s D N A$}

The combination of both FIT10 (cut-off with highest sensitivity for FIT in detecting AN in our study population) and mt-sDNA tests were considered positive if at least one test was positive. For both tests analyses, the laboratory technicians were blinded for the colonoscopy results limiting investigator bias.

\subsection{Colonoscopy}

The details of colonoscopy were described previously [29]. Colonoscopies were performed by experienced endoscopists. All detected polyps were described according to location, size, morphology, and macroscopic aspect and were directly removed for histological assessment according to standard protocol. The location of a polyp was classified as proximal when proximal to the splenic flexure. We analyzed the diagnostic accuracy of both stool tests according to the type of lesions detected during colonoscopy, for four groups: (1) any polyp (adenomas, serrated polyps), (2) AA (high-grade dysplasia, $\geq 25 \%$ villous component or $\geq 10 \mathrm{~mm}$ diameter), (3) ASL (dysplasia or $\geq 10 \mathrm{~mm}$ diameter), and (4) AN (AA, ASL, or CRC). All lesions were evaluated by the expert gastro-intestinal pathologist from the participating centers and all advanced lesions were reassessed by one expert pathologist (PS).

\subsection{Outcome Measures and Statistical Analysis}

A participant was considered to have a positive screen if at least one of the stool tests was considered positive at a specified cut-off level for both FIT and/or mt-sDNA tests at a single threshold. The reference was detection of colorectal lesions at colonoscopy. Furthermore, the sensitivity, specificity, positive predictive value (PPV), negative predictive value (NPV), positive likelihood ratio and negative likelihood ratio, and area under the curve (AUC) of the stool tests were evaluated for the four groups of lesions mentioned above (1-4). A 95\% confidence interval (CI) was calculated for these parameters assuming binominal distribution. FIT10 and mt-sDNA were compared using the McNemar test. For the calculations of the performance of the stool tests with respect to polyp location, we used the most advanced lesion. This was classified in order of most advanced as 1. AA, 2. ASL, 3. non-advanced adenoma, and 4 . non-advanced serrated lesion. If multiple advanced lesions were present ( 2 or more AA or ASL), then the largest was used as the most advanced lesion. Overall performance of FIT and mt-sDNA was evaluated by estimating the corresponding area under the receiver operating characteristic (ROC) curve. The ROC curve was represented by plotting the sensitivity versus 1 minus specificity. Values were compared using Chi square statistics. For analyses, SPSS V 22.0 was used. Results were reported according to the standards for reporting diagnostic accuracy [30].

\section{Results}

\subsection{Study Population}

Between February 2015 and February 2017, 101 HL survivors underwent a colonoscopy [7]. Figure 1 shows the flow of participants eligible for this study. The median age at colonoscopy of participants was 51 years (range 32-73), and over half of participants were male. No difference in treatment category, time between HL treatment and colonoscopy were observed between FIT and/or 
mt-sDNA groups. An overview of the baseline characteristics of the study population of the FIT and/or mt-sDNA cohorts is shown in Table 1.

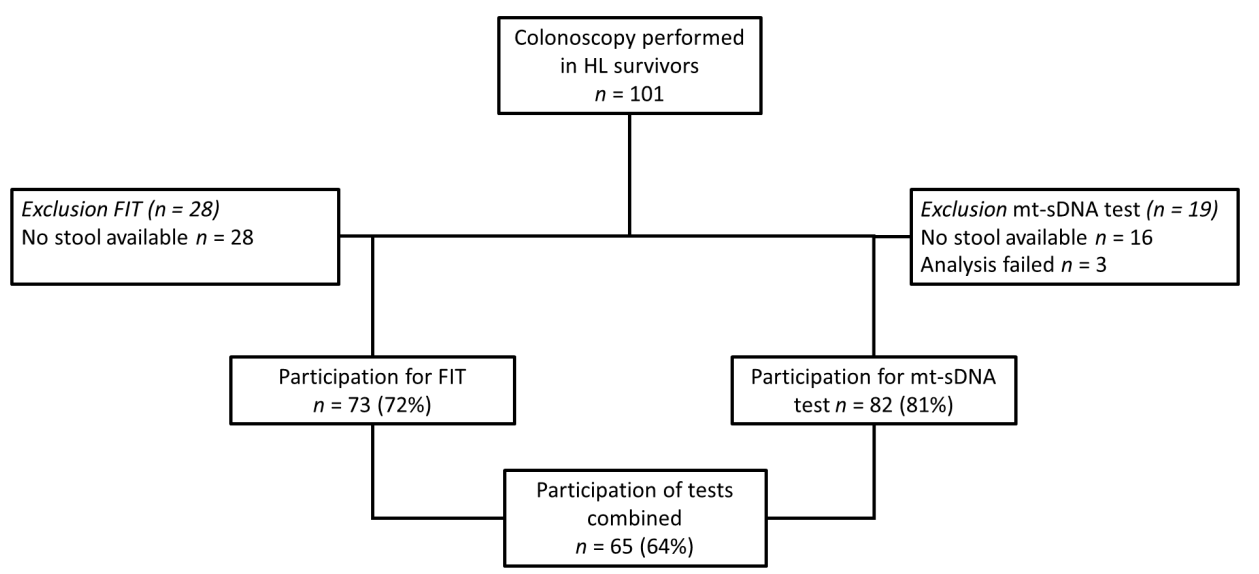

Figure 1. Study flow of Hodgkin lymphoma (HL) survivors who underwent a colonoscopy and participated in the fecal immunochemical test (FIT) and/or multi-target stool DNA test (mt-sDNA).

Table 1. Patient characteristics of Hodgkin Lymphoma (HL) survivors who underwent a colonoscopy and performed a fecal immunochemical test (FIT) and/or multi-target stool DNA test (mt-sDNA).

\begin{tabular}{|c|c|c|c|}
\hline Characteristic & $\begin{array}{l}\text { FIT Participants } \\
\quad(n=73)\end{array}$ & $\begin{array}{l}\text { Mt-sDNA Participants } \\
\quad(n=82)\end{array}$ & $\begin{array}{c}\text { FIT and Mt-sDNA } \\
\text { Participants }(n=65)\end{array}$ \\
\hline Male gender, $n(\%)$ & $44(60 \%)$ & $45(55 \%)$ & $40(62 \%)$ \\
\hline \multicolumn{4}{|l|}{ HL treatment category, $\%$} \\
\hline Abdominal RT + procarbazine & $25(34 \%)$ & $29(36 \%)$ & $24(37 \%)$ \\
\hline Procarbazine & $35(48 \%)$ & $38(46 \%)$ & $28(43 \%)$ \\
\hline Abdominal RT & $13(18 \%)$ & $15(18 \%)$ & $13(20 \%)$ \\
\hline $\begin{array}{l}\text { Time between HL treatment and } \\
\text { colonoscopy, median (range), y }\end{array}$ & $23(12-40)$ & $23(12-40)$ & $23(12-40)$ \\
\hline $\begin{array}{l}\text { Age at colonoscopy, median } \\
\text { (range), } y\end{array}$ & $51(32-73)$ & $51(32-73)$ & $50(32-73)$ \\
\hline \multicolumn{4}{|l|}{ Neoplastic lesions in cohorts } \\
\hline $\begin{array}{l}\text { No. per patient, median (range) } \\
\text { No. per patient, } \%\end{array}$ & $2(0-21)$ & $2(0-28)$ & $2(0-21)$ \\
\hline 0 & $21(29 \%)$ & $26(32 \%)$ & $21(32 \%)$ \\
\hline$\geq 1$ & $52(71 \%)$ & $56(68 \%)$ & $44(68 \%)$ \\
\hline \multicolumn{4}{|l|}{$\begin{array}{c}\text { Neoplasia detection per patient, } \\
\% \\
\text { Adenomas }\end{array}$} \\
\hline$\geq 1$ adenoma & $43(59 \%)$ & $44(54 \%)$ & $36(55 \%)$ \\
\hline $\begin{array}{l}\geq 1 \text { advanced adenoma } \\
\text { Serrated polyps }\end{array}$ & $13(18 \%)$ & $13(16 \%)$ & $12(19 \%)$ \\
\hline$\geq 1$ serrated polyps & $32(44 \%)$ & $35(43 \%)$ & $26(40 \%)$ \\
\hline$\geq 1$ advanced serrated lesion & $7(10 \%)$ & $10(12 \%)$ & $7(11 \%)$ \\
\hline Advanced neoplasia & $19(26 \%)$ & $22(27 \%)$ & $18(28 \%)$ \\
\hline
\end{tabular}

\subsection{Colonoscopy Results}

The cecum was reached during colonoscopy in all FIT and mt-sDNA participants. The median inspection time during withdrawal was 20 min (range 8-70), Boston Bowel Preparation score $>6$ was reported in all participants [7].

Table 1 shows the colonoscopy findings of FIT and/or mt-sDNA cohorts. In about one third of colonoscopy participants, no polyps were detected. AN was found in $26 \%$ (19 out of 73 ) of participants with an assessable FIT sample, 27\% (22 out of 82) with an assessable mt-sDNA, and in 28\% (18 out of 65) of participants with an assessable FIT and mt-sDNA. No CRC was found. One participant had both 
AA and ASL. Supplementary Table S1 shows the detection of colorectal neoplasia during colonoscopy in relation to FIT10 and/or mt-sDNA results.

\subsection{Fecal Immunochemical Test Results}

Of 73 participants, $12(16 \%)$ had a positive FIT result at a cut-off level of $10 \mathrm{ng} / \mathrm{mL}$ (FIT10). In the 12 FIT10 positive participants, any polyp was detected in $9(75 \%)$, AA in $4(33 \%)$, ASL in $3(25 \%)$, and AN in 7 (58\%). Among the 61 FIT10 participants with a negative test result, $12(20 \%)$ presented with AN at colonoscopy.

Table 2 summarizes the accuracy of FIT for any polyp, AA, ASL, and AN for three different cut-offs (FIT10, FIT15, and FIT20). FIT10 resulted in the highest sensitivity for AN of 37\% (95\% CI: 16-62) with a specificity of $91 \%$ (95\% CI: 80-97).

Table 2. Performance of fecal immunochemical test (FIT) at different cut-off levels for different disease outcomes.

\begin{tabular}{|c|c|c|c|c|c|c|c|}
\hline & $\begin{array}{l}\text { Number of } \\
\text { Events/Total }\end{array}$ & $\begin{array}{l}\text { Sensitivity } \\
(\%, 95 \% \text { CI })\end{array}$ & $\begin{array}{l}\text { Specificity } \\
(\%, 95 \% \text { CI })\end{array}$ & $\begin{array}{c}\text { PPV } \\
(\%, 95 \% \text { CI })\end{array}$ & $\begin{array}{c}\text { NPV } \\
(\%, 95 \% \text { CI })\end{array}$ & $\begin{array}{c}\text { LR+ } \\
(95 \% \mathrm{CI})\end{array}$ & $\begin{array}{c}\text { LR- } \\
(95 \% \mathrm{CI})\end{array}$ \\
\hline \multicolumn{8}{|l|}{ FIT10 } \\
\hline Any polyp & $52 / 73$ & $17(8-30)$ & $86(64-97)$ & 75 (47-91) & $30(25-34)$ & $1.21(0.36-4.04)$ & $0.96(0.78-1.20)$ \\
\hline AA & $13 / 73$ & $31(9-61)$ & 87 (75-94) & $33(15-59)$ & $85(80-89)$ & $2.31(0.82-6.53)$ & $0.80(0.55-1.16)$ \\
\hline ASL & $7 / 73$ & $43(10-82)$ & $86(76-94)$ & $25(10-49)$ & $93(88-96)$ & $3.14(1.10-8.97)$ & $0.66(0.35-1.27)$ \\
\hline $\mathrm{AN}$ & $19 / 73$ & $37(16-62)$ & $91(80-97)$ & $58(34-80)$ & $80(74-85)$ & $3.98(1.43-11.05)$ & $0.70(0.49-0.99)$ \\
\hline \multicolumn{8}{|l|}{ FIT15 } \\
\hline Any polyp & $52 / 73$ & $14(6-26)$ & $86(64-97)$ & $70(40-89)$ & $29(25-33)$ & $0.94(0.27-3.30)$ & $1.01(0.82-1.24)$ \\
\hline AA & $13 / 73$ & $31(9-61)$ & $90(70-96)$ & $40(18-67)$ & $86(81-90)$ & 3.08 (1.01-9.37) & $0.77(0.53-1.12)$ \\
\hline ASL & $7 / 73$ & $29(4-71)$ & 88 (78-95) & $20(6-49)$ & $92(88-95)$ & $2.36(0.62-9.00)$ & $0.81(0.50-1.31)$ \\
\hline $\mathrm{AN}$ & $19 / 73$ & $32(13-57)$ & $93(82-98)$ & $60(32-83)$ & $79(74-84)$ & $4.26(1.35-13.49)$ & $0.74(0.54-1.01)$ \\
\hline \multicolumn{8}{|l|}{ FIT20 } \\
\hline Any polyp & $52 / 73$ & $12(4-23)$ & 91 (70-99) & 75 (40-93) & $29(26-33)$ & $1.21(0.27-5.53)$ & $0.98(0.82-1.16)$ \\
\hline AA & $13 / 73$ & $23(5-54)$ & $92(82-97)$ & $38(14-69)$ & $85(81-88)$ & $2.77(0.75-10.16)$ & $0.84(0.62-1.14)$ \\
\hline ASL & $7 / 73$ & $29(4-71)$ & $91(81-97)$ & $25(8-57)$ & $92(88-95)$ & $3.14(0.78-12.72)$ & $0.79(0.49-1.26)$ \\
\hline $\mathrm{AN}$ & $19 / 73$ & $26(9-51)$ & $94(85-99)$ & $63(31-86)$ & 79 (73-83) & $4.74(1.25-17.95)$ & $0.78(0.59-1.03)$ \\
\hline
\end{tabular}

Any polyp = non-advanced and advanced adenoma and serrated polyp; AA = advanced adenoma; ASL = advanced serrated lesion; $\mathrm{AN}$ = advanced neoplasia; $\mathrm{CI}=$ confidence interval; $\mathrm{PPV}=$ positive predictive value; $\mathrm{NPV}=$ negative predictive value; $\mathrm{LR}+=$ likelihood ratio positive; $\mathrm{LR}-=$ likelihood ratio negative; FIT10 ( $\geq 10 \mu \mathrm{g} \mathrm{Hb} / \mathrm{g}$ feces); FIT15 ( $\geq 15 \mu \mathrm{g} \mathrm{Hb} / \mathrm{g}$ feces); FIT20 ( $\geq 20 \mu \mathrm{g} \mathrm{Hb} / \mathrm{g}$ feces).

The PPV of FIT10 for detecting AN was 58\% (95\% CI: 34-80). Corresponding NPV was $80 \%$ (95\% CI: 74-85). The area under the ROC curve of FIT for detecting AN was 0.68 (95\% CI: 0.54-0.82).

\subsection{Mt-sDNA Results}

Of the 82 participants with an evaluable mt-sDNA, $33(40 \%)$ had a positive test. In these mt-sDNA positives, 28 (85\%) participants had any polyp, 7 (21\%) an AA, $9(27 \%)$ an ASL, and $15(46 \%)$ an AN (one participant had both AA and ASL). In the $49 \mathrm{mt}$-sDNA negatives, colonoscopy detected in 7 (14\%) of the cases AN.

The mt-sDNA sensitivity for AN was $68 \%$ (95\% CI: 45-86) with a specificity of $70 \%$ (95\% CI: $57-81$ ). For ASL, mt-sDNA had an especially high sensitivity of 90\% (95\% CI: 56-98) with a corresponding specificity of 67\% (95\% CI: 55-77). The PPV and NPV for AN was 46\% (95\% CI: 34-57) and 86\% (95\% CI: 76-92), respectively. The positive and negative likelihood ratio for AN was 2.27 (95\% CI: 1.41-3.67) and 0.45 (95\% CI: 0.24-0.86), respectively. An overview is presented in Table 3. 
Table 3. Performance of multi-target stool DNA test (mt-sDNA).

\begin{tabular}{|c|c|c|c|c|c|c|c|}
\hline & $\begin{array}{l}\text { Number of } \\
\text { Events/Total }\end{array}$ & $\begin{array}{l}\text { Sensitivity } \\
(\%, 95 \% \mathrm{CI})\end{array}$ & $\begin{array}{c}\text { Specificity } \\
(\%, 95 \% \text { CI })\end{array}$ & $\begin{array}{c}\text { PPV } \\
(\%, 95 \% \text { CI })\end{array}$ & $\begin{array}{c}\text { NPV } \\
(\%, 95 \% \text { CI })\end{array}$ & $\begin{array}{c}\text { LR+ } \\
(95 \% \text { CI })\end{array}$ & $\begin{array}{c}\text { LR- } \\
(95 \% \mathrm{CI})\end{array}$ \\
\hline \multicolumn{8}{|l|}{ Mt-sDNA } \\
\hline Any polyp & $56 / 82$ & $50(36-67)$ & 81 (61-93) & 85 (71-93) & $43(35-51)$ & $2.60(1.13-5.96)$ & $0.62(0.45-0.85)$ \\
\hline AA & $13 / 82$ & $54(25-81)$ & $62(50-74)$ & $21(13-33)$ & 88 (79-93) & $1.43(0.79-2.57)$ & $0.74(0.40-1.37)$ \\
\hline ASL & $10 / 82$ & $90(56-98)$ & $67(55-67)$ & $27(20-36)$ & $98(88-100)$ & $2.70(1.83-3.97)$ & $0.15(0.02-0.97)$ \\
\hline $\mathrm{AN}$ & $22 / 82$ & $68(45-86)$ & $70(57-81)$ & $46(34-57)$ & $86(76-92)$ & $2.27(1.41-3.67)$ & $0.45(0.24-0.86)$ \\
\hline
\end{tabular}

Any polyp = non-advanced and advanced adenoma and serrated polyp; AA = advanced adenoma; ASL = advanced serrated lesion; $\mathrm{AN}$ = advanced neoplasia; $\mathrm{CI}=$ confidence interval; $\mathrm{PPV}=$ positive predictive value; $\mathrm{NPV}=$ negative predictive value; $\mathrm{LR}+=$ likelihood ratio positive; $\mathrm{LR}-=$ likelihood ratio negative.

The AUC for ROC curve for detecting AN was 0.76 (95\% CI: 0.63-0.89). The sensitivity of mt-sDNA is significantly higher compared to the sensitivity of FIT10 ( $p$ value 0.043 ).

\subsection{FIT10 and/or Mt-sDNA Results Combined}

The combination of a positive FIT10 and/or mt-sDNA resulted in $29(45 \%$ of 65$)$ positive results, of which 12 (41\% of 29$)$ had an AN. Of the 29 positive results, 22 (76\%) had polyps, $6(21 \%)$ had AA, 7 $(24 \%)$ had ASL, and $12(41 \%)$ had AN. Of the 36 participants with both test results negative, $6(17 \%)$ had an AN.

The sensitivity and specificity for detecting AN for combined tests were 67\% (95\% CI: 41-87) and 64\% (95\% CI: 49-77), respectively (Table 4).

Table 4. Performance of fecal immunochemical test at cut-off of $\geq 10 \mu \mathrm{g} \mathrm{Hb} / \mathrm{g}$ feces (FIT10) and multi-target stool DNA test (mt-sDNA) combined.

\begin{tabular}{cccccccc}
\hline & $\begin{array}{c}\text { Number of } \\
\text { Events/Total }\end{array}$ & $\begin{array}{c}\text { Sensitivity } \\
(\mathbf{\%}, \mathbf{9 5} \% \mathbf{C I})\end{array}$ & $\begin{array}{c}\text { Specificity } \\
\mathbf{( \% , 9 5 \% ~ C I )}\end{array}$ & $\begin{array}{c}\text { PPV (\%, } \\
\mathbf{9 5 \%} \mathbf{~ C I})\end{array}$ & $\begin{array}{c}\text { NPV (\%, } \\
\mathbf{9 5 \%} \text { CI) }\end{array}$ & LR+ (95\% CI) & LR- (95\% CI) \\
\hline $\begin{array}{c}\text { Combined } \\
\text { stool test }\end{array}$ & & & & & & & \\
Any polyp & $24 / 65$ & $50(35-65)$ & $66(43-85)$ & $76(62-86)$ & $39(29-49)$ & $1.50(0.77-2.94)$ & $0.75(0.49-1.14)$ \\
AA & $12 / 65$ & $50(21-79)$ & $57(42-70)$ & $21(12-33)$ & $83(73-90)$ & $1.15(0.61-2.19)$ & $0.88(0.48-1.63)$ \\
ASL & $7 / 65$ & $100(59-100)$ & $62(48-75)$ & $24(19-31)$ & $100 *$ & $2.64(1.90-3.66)$ & 0 \\
AN & $18 / 65$ & $67(41-87)$ & $64(49-77)$ & $41(30-54)$ & $83(72-91)$ & $1.84(1.12-3.04)$ & $0.52(0.26-1.04)$ \\
\hline
\end{tabular}

Any polyp = non-advanced and advanced adenoma and serrated polyp; AA = advanced adenoma; ASL = advanced serrated lesion; $\mathrm{AN}=$ advanced neoplasia; $\mathrm{CI}=$ confidence interval; $\mathrm{PPV}=$ positive predictive value; $\mathrm{NPV}=$ negative predictive value; ${ }^{*}=$ calculation not possible (due to no false negative results); $\mathrm{LR}+=$ likelihood ratio positive; LR- = likelihood ratio negative; FIT10 ( $\geq 10 \mu \mathrm{g} \mathrm{Hb} / \mathrm{g}$ feces).

\subsection{Diagnostic Accuracy of FIT and/or Mt-sDNA for the Most Advanced Lesion Per Participant Based on Location}

FIT10 revealed a low sensitivity for the most advanced lesion, in the proximal colon location of only $13 \%$ (95\% CI: 4-31) and in distal location of $23 \%$ (95\% CI: $8-45)$. The highest sensitivity for proximal lesions was obtained with the mt-sDNA (56\% (95\% CI: 38-74)). For distal neoplasia, mt-sDNA had a sensitivity of $42 \%$ (95\% CI: 22-63). The sensitivity of the FIT10 and/or mt-sDNA was $44 \%$ (95\% CI: 22-69) for proximal location (Table 5). 
Table 5. Accuracy of fecal immunochemical test at cut-off of $\geq 10 \mu \mathrm{g} \mathrm{Hb} / \mathrm{g}$ feces (FIT10) and/or multi-target stool DNA test (mt-sDNA) according to location of most advanced neoplasia.

\begin{tabular}{|c|c|c|}
\hline & Sensitivity $(\%, 95 \%$ CI $)$ & Specificity $(\%, 95 \%$ CI $)$ \\
\hline \multicolumn{3}{|l|}{ Proximal neoplasia * } \\
\hline FIT10 & $13(4-31)$ & $77(55-92)$ \\
\hline Mt-sDNA & $56(38-74)$ & $58(37-78)$ \\
\hline FIT10 and mt-sDNA & $54(33-73)$ & $56(31-78)$ \\
\hline \multicolumn{3}{|l|}{ Distal neoplasia * } \\
\hline FIT10 & $23(8-45)$ & 87 (69-96) \\
\hline Mt-sDNA & $42(22-63)$ & $44(26-62)$ \\
\hline FIT10 and mt-sDNA & $44(22-69)$ & $46(27-67)$ \\
\hline
\end{tabular}

* Proximal neoplasia = proximal to (and including) flexura lienalis; Distal neoplasia = Distal to flexura lienalis; FIT10 ( $\geq 10 \mu \mathrm{g} \mathrm{Hb} / \mathrm{g}$ feces).

\section{Discussion}

In this study, we evaluated the diagnostic accuracy for FIT and/or mt-sDNA in HL survivors treated with abdominal radiotherapy and/or procarbazine, with colonoscopy as a reference, in order to evaluate their potential as non-invasive surveillance modalities for HL survivors. We show that the mt-sDNA had the highest sensitivity for detecting AN in HL survivors (68\%) with a corresponding specificity of $70 \%$ and FIT10 combined with mt-sDNA resulted in a sensitivity of $67 \%$ with a specificity of $64 \%$. The sensitivity of FIT10 for detecting AN was only 37\%, but specificity was higher (91\%). Since this is a unique patient population, our findings are not generalizable to other groups.

It can be argued that the sensitivity of stool tests is more important than specificity in HL survivors with an indication for surveillance because of the high risk for CRC. Relative risks for CRC between 2 and 7 have been reported compared to the general population [1-4,31]. Aside from the increased risk for CRC, HL survivors also have a higher prevalence of (advanced) serrated lesions, serrated polyposis syndrome, and AA at a younger age compared to the general population [7]. Furthermore, colorectal lesions are more frequently proximal [7]. We evaluated whether stool tests can be used as a surveillance strategy with colonoscopy for stool test positive individuals. However, the optimal surveillance strategy and surveillance interval is not only defined by diagnostic test performance. A cost-effectiveness analysis can expand the knowledge about the optimal surveillance strategy, taking also participation into consideration.

Due to the increased risk of CRC, other criteria for optimal performance of stool tests should be used compared to an average-risk population-based screening [31-36]. In this high-risk-group, it can be argued that detection of precursor colorectal neoplasia is extra important due to the higher prevalence of these lesions and CRC. Little is known about the diagnostic accuracy of stool tests in high-risk groups.

Cost-effectiveness analysis showed that FIT10 (10 $\mu \mathrm{g} \mathrm{Hb} / \mathrm{g}$ feces) would be the most optimal cut-off level in the average risk population, with a high sensitivity for CRC [33]. The FIT10 sensitivity for detecting AN was low in HL survivors, around $40 \%$, but comparable with sensitivity data in average risk and above-average risk populations [27,34-36].

We detected a higher sensitivity of $68 \%$ for AN using mt-sDNA compared to FIT10 in HL survivors. Presently, the mt-sDNA is being evaluated for surveillance in a high-risk population with previous CRC or adenomas/serrated polyps or with familial risk [37]. Previously, triennial mt-sDNA was considered not cost-effective in a cohort of previously unscreened 65-year-olds [38]. Of interest, in our study, a high sensitivity of $90 \%$ for mt-sDNA was found for ASL, which is higher than the $42 \%$ and $55 \%$ reported in prior publications [24,39]. Because of the high prevalence of ASL as detected during colonoscopy in HL survivors [7], this strengthens the usefulness of mt-sDNA in this patient group.

The mt-sDNA was off label use in HL survivors, but is interesting since the long-term effect of chemotherapy and/or radiation for these patients on the colonic epithelium, especially with respect to background methylation and cell turnover, has not been elucidated. 
Combining FIT10 and the mt-sDNA test resulted in similar sensitivity and specificity compared to the mt-sDNA test only. Therefore, this combination does not add to the test performance.

The mt-sDNA was more sensitive than FIT for detecting the most advanced lesions proximal in the colon in comparison to distal, while previously, a higher sensitivity for distal advanced neoplasia has been described [24]. This might be explained by the fact that more serrated lesions were found in this population and serrated lesions were mostly proximal located. For the most advanced lesions, FIT10 had a higher sensitivity for distal compared to proximal, which has also been reported in another study [24].

The main question is whether stool tests should be considered accurate enough to detect AN in this known high-risk population. Perhaps a higher diagnostic accuracy is needed in this group for detecting AN. When only performing a FIT10 in HL survivors, comparable to the current population-based CRC screening program in the Netherlands, $20 \%$ of AN would have been missed due to a false negative result. AN would still have been missed in $14 \%$ due to a negative result of mt-sDNA. Of note, this study only shows the results of one-time FIT and/or mt-sDNA. It has been proposed that repeating FIT and/or the mt-sDNA test (for instance every biennial or triennial testing) would result in a higher program sensitivity [40]. Further research is necessary to determine the most optimal surveillance interval.

Several advantages exist of performing stool tests as a first step in CRC surveillance in HL survivors. Firstly, stool tests could help to select which HL survivors should undergo a colonoscopy, especially in HL survivors unwilling to undergo a colonoscopy. Especially since it is known that cancer survivors generally undergo more medical interventions compared to the general population, including preventive measurements [41]. Additionally, undergoing a colonoscopy can be burdensome for the participant [10]. In our study, only $41 \%$ of eligible HL survivors agreed to undergo colonoscopy [7]. Providing a stool test could be an acceptable surveillance technique in HL survivors who do not want to undergo colonoscopy surveillance, thereby improving the participation rate in this population and eventually resulting in an increase of the AN detection rate. Of note, in our study population, the participation rate of performing stool test was acceptable ( $72 \%$ for FIT and $81 \%$ for $\mathrm{mt}$-sDNA). We do not know what the participation of stool tests will be in the whole HL survivor group. We only have data from the colonoscopy participants.

Directly performing a colonoscopy has been shown to reduce CRC incidence and mortality in other high-risk populations [42,43]. Precursor lesions of CRC can be endoscopically removed, thereby reducing the CRC incidence [14]. This strengthens the fact that colonoscopy is the first choice for colonoscopy surveillance in high-risk-groups, emphasizing the need in HL survivors, but currently participation is too low.

This study has several strengths. To our knowledge, this is the first study to investigate the diagnostic accuracy of stool tests in cancer survivors with a known increased risk of developing CRC $[1,2,5,7]$. FIT has been evaluated in intermediate-risk individuals following colonoscopy screening and in individuals with a personal or familial history of CRC, but not in other established high-risk groups $[27,44]$. Another strength is that this population was screening-naïve and received both stool tests and a primary colonoscopy [29]. Previous screening can result in a lower prevalence of AN in a population and therefore impact test performance and especially yield lower positive predictive values [45]. Furthermore, researchers were blinded from results of the colonoscopy, which prevented investigator bias.

This study has several limitations. Firstly, the sample size is small. In accordance with previous studies, the participation rate of HL survivors who underwent a colonoscopy was low $[7,17,40]$. Also, the colonoscopy itself as a reference is not $100 \%$ sensitive, since colorectal neoplasia can be missed [46].

Colonoscopy is considered a good surveillance modality for high-risk populations. However, stool tests may be a possible alternative surveillance modality for selection for colonoscopy in participants unwilling to undergo a colonoscopy. The main advantages are the non-invasive character of the test and a potential increased participation rate with a stool test compared to primary colonoscopy 
surveillance. A cost-effectiveness analysis is necessary to determine the optimal surveillance test for HL survivors being FIT, mt-sDNA test, or primary colonoscopy $[38,47,48]$.

\section{Conclusions}

Sensitivity of FIT10 is limited for AN in HL survivors. The mt-sDNA test has a relative high sensitivity in detecting advanced neoplasia, especially for advanced serrated polyps. Stool tests can be used to select for colonoscopy as an alternative CRC surveillance modality in HL survivors, potentially increasing the participation rate in HL survivors unable or unwilling to undergo a colonoscopy. Cost-effectiveness analyses will be performed to determine the optimal strategy.

Supplementary Materials: The following are available online at http://www.mdpi.com/2077-0383/9/1/190/s1, Table S1: Yield of colonoscopy in relation to FIT10, FIT15, FIT20, mt-sDNA and FIT10 and/or mt-sDNA result combined.

Author Contributions: Conceptualization, B.Y., L.R., B.C. and M.v.L.; Methodology, B.Y., L.R., B.C. and M.v.L.; Validation, B.Y., L.R., B.C. and M.v.L.; formal analysis, B.Y.; investigation, B.Y., L.R., M.S., L.M., T.B., W.V., M.L., P.S., B.C. and M.v.L.; resources, G.M.; data curation, B.Y. and L.R.; writing-original draft preparation, B.Y., L.R., B.C. and M.v.L.; writing-review and editing, B.Y., L.R., B.C. and M.v.L., with input from M.S., L.M., T.B., B.A., J.P.d.B., P.L., C.J., E.P., J.R. (Judith Roesink), J.R. (John Raemaekers), R.v.d.M., I.L.-V., A.G., W.V., M.L.G.M., F.v.L. and P.S.; visualization, B.Y.; supervision, M.v.L.; project administration, L.R.; funding acquisition, L.R. and M.v.L. All authors have read and agreed to the published version of the manuscript.

Funding: The colonoscopy and FIT (OC-Sensor Eiken Chemical, Tokyo, Japan) was funded by the Dutch Digestive Disease Foundation (Maag Lever Darm Stichting) through funding project FP 14-04. Mt-sDNA tests were provided by Exact Sciences (Madison, WI, USA).

Acknowledgments: We would like to thank Exact Sciences Corporation (Madison, WI, USA) for providing the equipment necessary for stool collection and homogenizing of the multitarget stool DNA test (mt-sDNA, Cologuard) and performing the analysis. We would like to acknowledge the NKI- AVL Core Facility Molecular Pathology \& Biobanking (CFMPB) for supplying NKI-AVL Biobank material and/or lab support. We would like to thank Meta van Lanschot for helping with the study design for the multitarget stool test.

Conflicts of Interest: Monique E. van Leerdam obtained funding from the Dutch Digestive Disease Foundation (Maag Lever Darm Stichting). Drs. Berger and Lidgard are employees and equity holders of Exact Sciences Corporation. G.A. Meijer has research collaborations with Sysmex and Sentinel for other studies regarding early detection of colorectal cancer and has several patents pending for multiple applications of CRC-related biomarkers. The companies provide materials and equipment. All other authors have no conflicts of interest to declare. The funders had no role in the design of the study; in the collection, analyses, or interpretation of data.

\section{References}

1. Hodgson, D.C.; Gilbert, E.S.; Dores, G.M.; Schonfeld, S.J.; Lynch, C.F.; Storm, H.; Hall, P.; Langmark, F.; Pukkala, E.; Andersson, M.; et al. Long-Term Solid Cancer Risk Among 5-Year Survivors of Hodgkin's Lymphoma. J. Clin. Oncol. 2007, 25, 1489-1497. [CrossRef] [PubMed]

2. Schaapveld, M.; Aleman, B.M.; Van Eggermond, A.M.; Janus, C.P.; Krol, A.D.; Van Der Maazen, R.W.; Roesink, J.; Raemaekers, J.M.; De Boer, J.P.; Zijlstra, J.M.; et al. Second Cancer Risk Up to 40 Years after Treatment for Hodgkin's Lymphoma. N. Engl. J. Med. 2015, 373, 2499-2511. [CrossRef] [PubMed]

3. Swerdlow, A.J.; Higgins, C.D.; Smith, P.; Cunningham, D.; Hancock, B.W.; Horwich, A.; Hoskin, P.J.; Lister, T.A.; Radford, J.A.; Rohatiner, A.Z.S.; et al. Second Cancer Risk After Chemotherapy for Hodgkin's Lymphoma: A Collaborative British Cohort Study. J. Clin. Oncol. 2011, 29, 4096-4104. [CrossRef] [PubMed]

4. Nottage, K.; McFarlane, J.; Krasin, M.J.; Li, C.; Srivastava, D.; Robison, L.L.; Hudson, M.M. Secondary Colorectal Carcinoma After Childhood Cancer. J. Clin. Oncol. 2012, 30, 2552-2558. [CrossRef]

5. Van Eggermond, A.M.; Schaapveld, M.; Janus, C.P.; De Boer, J.P.; Krol, A.D.; Zijlstra, J.M.; Van Der Maazen, R.W.; Kremer, L.C.; Van Leerdam, M.E.; Louwman, M.W.; et al. Infradiaphragmatic irradiation and high procarbazine doses increase colorectal cancer risk in Hodgkin lymphoma survivors. Br. J. Cancer 2017, 117, 306-314. [CrossRef]

6. Henderson, T.O.; Oeffinger, K.C.; Whitton, J.; Leisenring, W.; Neglia, J.; Meadows, A.; Crotty, C.; Rubin, D.T.; Diller, L.; Inskip, P.; et al. Secondary gastrointestinal cancer in childhood cancer survivors: A cohort study. Ann. Intern. Med. 2012, 156, 757. [CrossRef] 
7. Rigter, L.S.; Spaander, M.C.W.; Aleman, B.M.P.; Bisseling, T.M.; Moons, L.M.; Cats, A.; Lugtenburg, P.J.; Janus, C.P.M.; Petersen, E.J.; Roesink, J.M.; et al. High prevalence of advanced colorectal neoplasia and serrated polyposis syndrome in Hodgkin lymphoma survivors. Cancer 2019, 125, 990-999. [CrossRef]

8. Roos, V.H.; Mangas-Sanjuan, C.; Rodriguez-Girondo, M.; Prado, L.M.; Steyerberg, E.W.; Bossuyt, P.M.; Dekker, E.; Jover, R.; Van Leerdam, M.E. Effects of Family History on Relative and Absolute Risks for Colorectal Cancer: A Systematic Review and Meta-Analysis. Clin. Gastroenterol. Hepatol. 2019, 17, 2657-2667.e9. [CrossRef]

9. Atkin, W.; Dadswell, E.; Wooldrage, K.; Kralj-Hans, I.; Von Wagner, C.; Edwards, R.; Yao, G.; Kay, C.; Burling, D.; Faiz, O.; et al. Computed tomographic colonography versus colonoscopy for investigation of patients with symptoms suggestive of colorectal cancer (SIGGAR): A multicentre randomised trial. Lancet 2013, 381, 1194-1202. [CrossRef]

10. Von Wagner, C.; Ghanouni, A.; Halligan, S.; Smith, S.; Dadswell, E.; Lilford, R.J.; Morton, D.; Atkin, W.; Wardle, J. Patient Acceptability and Psychologic Consequences of CT Colonography Compared with Those of Colonoscopy: Results from a Multicenter Randomized Controlled Trial of Symptomatic Patients. Radiology 2012, 263, 723-731. [CrossRef]

11. Kim, S.Y.; Kim, H.-S.; Park, H.J. Adverse events related to colonoscopy: Global trends and future challenges. World J. Gastroenterol. 2019, 25, 190-204. [CrossRef]

12. Zauber, A.G.; Winawer, S.J.; O’Brien, M.J.; Lansdorp-Vogelaar, I.; Van Ballegooijen, M.; Hankey, B.F.; Shi, W.; Bond, J.H.; Schapiro, M.; Panish, J.F.; et al. Colonoscopic polypectomy and long-term prevention of colorectal-cancer deaths. N. Engl. J. Med. 2012, 366, 687-696. [CrossRef] [PubMed]

13. Nishihara, R.; Wu, K.; Lochhead, P.; Morikawa, T.; Liao, X.; Qian, Z.R.; Inamura, K.; Kim, S.A.; Kuchiba, A.; Yamauchi, M.; et al. Long-term colorectal-cancer incidence and mortality after lower endoscopy. N. Engl. J. Med. 2013, 369, 1095-1105. [CrossRef] [PubMed]

14. Citarda, F.; Tomaselli, G.; Capocaccia, R.; Barcherini, S.; Crespi, M.; The Italian Multicentre Study Group. Efficacy in standard clinical practice of colonoscopic polypectomy in reducing colorectal cancer incidence. Gut 2001, 48, 812-815. [CrossRef] [PubMed]

15. Winawer, S.J.; Zauber, A.G.; Ho, M.N.; O’Brien, M.J.; Gottlieb, L.S.; Sternberg, S.S.; Waye, J.D.; Schapiro, M.; Bond, J.H.; Panish, J.F.; et al. Prevention of Colorectal Cancer by Colonoscopic Polypectomy. N. Engl. J. Med. 1993, 329, 1977-1981. [CrossRef] [PubMed]

16. Lieberman, D.A.; Rex, U.K.; Winawer, S.J.; Giardiello, F.M.; Johnson, D.A.; Levin, T.R. Guidelines for Colonoscopy Surveillance After Screening and Polypectomy: A Consensus Update by the US Multi-Society Task Force on Colorectal Cancer. Gastroenterol. 2012, 143, 844-857. [CrossRef] [PubMed]

17. Quintero, E.; Castells, A.; Bujanda, L.; Cubiella, J.; Salas, D.; Lanas, A.; Andreu, M.; Carballo, F.; Morillas, J.D.; Hernández, C.; et al. Colonoscopy versus Fecal Immunochemical Testing in Colorectal-Cancer Screening. N. Engl. J. Med. 2012, 366, 697-706. [CrossRef]

18. Kapidzic, A.; Grobbee, E.J.; Hol, L.; Van Roon, A.H.; Van Vuuren, A.J.; Spijker, W.; Izelaar, K.; Van Ballegooijen, M.; Kuipers, E.J.; Van Leerdam, M.E. Attendance and Yield Over Three Rounds of Population-Based Fecal Immunochemical Test Screening. Am. J. Gastroenterol. 2014, 109, 1257-1264. [CrossRef]

19. Stegeman, I.; Van Doorn, S.; Mundt, M.; Mallant-Hent, R.; Bongers, E.; Elferink, M.; Fockens, P.; Stroobants, A.; Bossuyt, P.; Dekker, E. Participation, yield, and interval carcinomas in three rounds of biennial FIT-based colorectal cancer screening. Cancer Epidemiol. 2015, 39, 388-393. [CrossRef]

20. van Roon, A.H.; Goede, S.L.; van Ballegooijen, M.; van Vuuren, A.J.; Looman, C.W.; Biermann, K.; Reijerink, J.C.; Mannetje, H.; van der Togt, A.C.; Habbema, J.D.; et al. Random comparison of repeated faecal immunochemical testing at different intervals for population-based colorectal cancer screening. Gut 2013, 62, 409-415. [CrossRef]

21. Carethers, J.M. Fecal DNA Testing for Colorectal Cancer Screening. Annu. Rev. Med. 2019, 71. [CrossRef] [PubMed]

22. Zhai, R.L.; Xu, F.; Zhang, P.; Zhang, W.L.; Wang, H.; Wang, J.L.; Cai, K.L.; Long, Y.P.; Lu, X.M.; Tao, K.X.; et al. The Diagnostic Performance of Stool DNA Testing for Colorectal Cancer: A Systematic Review and Meta-Analysis. Medicine 2016, 95, e2129. [CrossRef] [PubMed]

23. Bosch, L.J.; Carvalho, B.; Fijneman, R.J.; Jimenez, C.R.; Pinedo, H.M.; Van Engeland, M.; Meijer, G.A. Molecular Tests for Colorectal Cancer Screening. Clin. Color. Cancer 2011, 10, 8-23. [CrossRef] [PubMed] 
24. Imperiale, T.F.; Ransohoff, D.F.; Itzkowitz, S.H.; Levin, T.R.; Lavin, P.; Lidgard, G.P.; Ahlquist, D.A.; Berger, B.M. Multitarget stool DNA testing for colorectal-cancer screening. N. Engl. J. Med. 2014, 370, 1287-1297. [CrossRef]

25. Bradshaw, D.; Gans, C.; Jones, P.; Rizzuto, G.; Steiner, N.; Mitton, W.; Ng, J.; Koester, R.; Hartzman, R.; Hurley, C. Novel HLA-A locus alleles including A*01012, A*0306, A*0308, A*2616, A*2617, A*3009, A*3206, $A * 3403, A^{*} 3602$ and $A * 6604$. Tissue Antigens 2002, 59, 325-327. [CrossRef]

26. CBO. Hereditary Colorectal Cancer, National Guideline. 2015. Available online: https://www.mdl.nl/sites/www. mdl.nl/files/richlijnen/Erfelijke_darmkanker_-_december_2015_def.pdf (accessed on 4 November 2019).

27. Katsoula, A.; Paschos, P.; Haidich, A.-B.; Tsapas, A.; Giouleme, O. Diagnostic Accuracy of Fecal Immunochemical Test in Patients at Increased Risk for Colorectal Cancer: A Meta-analysis. JAMA Intern. Med. 2017, 177, 1110-1118. [CrossRef]

28. Van Leerdam, M.E.; Roos, V.H.; Van Hooft, J.E.; Dekker, E.; Jover, R.; Kaminski, M.F.; Latchford, A.; Neumann, H.; Pellisé, M.; Saurin, J.-C.; et al. Endoscopic management of polyposis syndromes: European Society of Gastrointestinal Endoscopy (ESGE) Guideline. Endoscopy 2019, 51, 877-895. [CrossRef]

29. Rigter, L.S.; Spaander, M.C.W.; Moons, L.M.; Bisseling, T.M.; Aleman, B.M.P.; De Boer, J.P.; Lugtenburg, P.J.; Janus, C.P.M.; Petersen, E.J.; Roesink, J.M.; et al. Colorectal cancer surveillance in Hodgkin lymphoma survivors at increased risk of therapy-related colorectal cancer: Study design. BMC Cancer 2017, 17, 112. [CrossRef]

30. Cohen, J.F.; Korevaar, D.A.; Altman, U.G.; Bruns, D.E.; Gatsonis, C.A.; Hooft, L.; Irwig, L.; Levine, D.; Reitsma, J.B.; De Vet, H.C.W.; et al. STARD 2015 guidelines for reporting diagnostic accuracy studies: Explanation and elaboration. BMJ Open 2016, 6, 012799. [CrossRef]

31. Gies, A.; Bhardwaj, M.; Stock, C.; Schrotz-King, P.; Brenner, H. Quantitative fecal immunochemical tests for colorectal cancer screening. Int. J. Cancer 2018, 143, 234-244. [CrossRef]

32. Toes-Zoutendijk, E.; van Leerdam, M.E.; Dekker, E.; van Hees, F.; Penning, C.; Nagtegaal, I.; van der Meulen, M.P.; van Vuuren, A.J.; Kuipers, E.J.; Bonfrer, J.M.G.; et al. Real-Time Monitoring of Results During First Year of Dutch Colorectal Cancer Screening Program and Optimization by Altering Fecal Immunochemical Test Cut-Off Levels. Gastroenterology 2017, 152, 767-775. [CrossRef] [PubMed]

33. Wilschut, J.A.; Hol, L.; Dekker, E.; Jansen, J.B.; Van Leerdam, M.E.; Lansdorp-Vogelaar, I.; Kuipers, E.J.; Habbema, J.D.F.; Van Ballegooijen, M. Cost-effectiveness Analysis of a Quantitative Immunochemical Test for Colorectal Cancer Screening. Gastroenterology 2011, 141, 1648-1655. [CrossRef] [PubMed]

34. Chang, L.-C.; Shun, C.-T.; Hsu, W.-F.; Tu, C.-H.; Tsai, P.-Y.; Lin, B.-R.; Liang, J.-T.; Wu, M.-S.; Chiu, H.-M. Fecal Immunochemical Test Detects Sessile Serrated Adenomas and Polyps With a Low Level of Sensitivity. Clin. Gastroenterol. Hepatol. 2017, 15, 872-879. [CrossRef]

35. Zorzi, M.; Senore, C.; Da Re, F.; Barca, A.; Bonelli, L.A.; Cannizzaro, R.; De Pretis, G.; Di Furia, L.; Di Giulio, E.; Mantellini, P.; et al. Detection rate and predictive factors of sessile serrated polyps in an organised colorectal cancer screening programme with immunochemical faecal occult blood test: The EQuIPE study (Evaluating Quality Indicators of the Performance of Endoscopy). Gut 2016, 66, 1233-1240. [CrossRef] [PubMed]

36. Cock, C.; Anwar, S.; Byrne, S.E.; Meng, R.; Pedersen, S.; Fraser, R.J.L.; Young, G.P.; Symonds, E.L. Low Sensitivity of Fecal Immunochemical Tests and Blood-Based Markers of DNA Hypermethylation for Detection of Sessile Serrated Adenomas/Polyps. Dig. Dis. Sci. 2019, 64, 2555-2562. [CrossRef] [PubMed]

37. Van Lanschot, M.C.J.; Carvalho, B.; Coupé, V.M.H.; Van Engeland, M.; Dekker, E.; Meijer, G.A. Molecular stool testing as an alternative for surveillance colonoscopy: A cross-sectional cohort study. BMC Cancer 2017, 17, 116. [CrossRef]

38. Naber, S.K.; Knudsen, A.B.; Zauber, A.G.; Rutter, C.M.; Fischer, S.E.; Pabiniak, C.J.; Soto, B.; Kuntz, K.M.; Lansdorp-Vogelaar, I. Cost-effectiveness of a multitarget stool DNA test for colorectal cancer screening of Medicare beneficiaries. PLoS ONE 2019, 14, e0220234. [CrossRef]

39. Heigh, R.I.; Yab, T.C.; Taylor, W.R.; Hussain, F.T.N.; Smyrk, T.C.; Mahoney, U.W.; Domanico, M.J.; Berger, B.M.; Lidgard, G.P.; Ahlquist, D.A. Detection of Colorectal Serrated Polyps by Stool DNA Testing: Comparison with Fecal Immunochemical Testing for Occult Blood (FIT). PLoS ONE 2014, 9, e85659. [CrossRef] 
40. De Wijkerslooth, T.R.; Stoop, E.M.; Bossuyt, P.M.; Meijer, G.A.; Van Ballegooijen, M.; Van Roon, A.H.C.; Stegeman, I.; Kraaijenhagen, R.A.; Fockens, P.; Van Leerdam, M.E.; et al. Immunochemical Fecal Occult Blood Testing Is Equally Sensitive for Proximal and Distal Advanced Neoplasia. Am. J. Gastroenterol. 2012, 107, 1570-1578. [CrossRef]

41. Van Leeuwen, F.E.; Ng, A.K. Late sequelae in Hodgkin lymphoma survivors. Hematol. Oncol. 2017, 35, 60-66. [CrossRef]

42. Brenner, H.; Stock, C.; Hoffmeister, M. Effect of screening sigmoidoscopy and screening colonoscopy on colorectal cancer incidence and mortality: Systematic review and meta-analysis of randomised controlled trials and observational studies. BMJ 2014, 348, g2467. [CrossRef] [PubMed]

43. Järvinen, H.J.; Aarnio, M.; Mustonen, H.; Aktan-Collan, K.; Aaltonen, L.A.; Peltomäki, P.; De La Chapelle, A.; Mecklin, J. Controlled 15-year trial on screening for colorectal cancer in families with hereditary nonpolyposis colorectal cancer. Gastroenterology 2000, 118, 829-834. [CrossRef]

44. Cross, A.J.; Wooldrage, K.; Robbins, E.C.; Kralj-Hans, I.; MacRae, E.; Piggott, C.; Stenson, I.; Prendergast, A.; Patel, B.; Pack, K.; et al. Faecal immunochemical tests (FIT) versus colonoscopy for surveillance after screening and polypectomy: A diagnostic accuracy and cost-effectiveness study. Gut 2019, 68, 1642-1652. [CrossRef] [PubMed]

45. Steele, R.J.; McClements, P.; Watling, C.; Libby, G.; Weller, D.; Brewster, D.H.; Black, R.; Carey, F.A.; Fraser, C.G. Interval cancers in a FOBT-based colorectal cancer population screening programme: Implications for stage, gender and tumour site. Gut 2012, 61, 576-581. [CrossRef]

46. Van Rijn, J.C.; Reitsma, J.B.; Stoker, J.; Bossuyt, P.M.; Van Deventer, S.J.; Dekker, E. Polyp Miss Rate Determined by Tandem Colonoscopy: A Systematic Review. Am. J. Gastroenterol. 2006, 101, 343-350. [CrossRef]

47. Lansdorp-Vogelaar, I.; Goede, S.L.; Bosch, L.J.; Melotte, V.; Carvalho, B.; Van Engeland, M.; Meijer, G.A.; De Koning, H.J.; Van Ballegooijen, M. Cost-effectiveness of High-performance Biomarker Tests vs Fecal Immunochemical Test for Noninvasive Colorectal Cancer Screening. Clin. Gastroenterol. Hepatol. 2018, 16, 504-512. [CrossRef]

48. Gini, A.; Meester, R.G.S.; Keshavarz, H.; Oeffinger, K.C.; Ahmed, S.; Hodgson, D.C.; Lansdorp-Vogelaar, I. Cost-Effectiveness of Colonoscopy-Based Colorectal Cancer Screening in Childhood Cancer Survivors. J. Natl. Cancer Inst. 2019, 111, 1161-1169. [CrossRef] 